\title{
Characterization of microbial communities in a granular activated carbon-sand dual media filter for drinking water treatment
}

\author{
S. Feng $\cdot$ C. Chen $\cdot$ Q. F. Wang $\cdot$ X. J. Zhang $\cdot$ \\ Z. Y. Yang $\cdot$ S. G. Xie
}

Received: 3 March 2011 / Revised: 9 December 2011/Accepted: 9 April 2012/Published online: 12 February 2013

(C) Islamic Azad University (IAU) 2013

\begin{abstract}
Modification of conventional rapid sand filter into granular activated carbon-sand dual media filter has become increasingly attractive to drinking water producers in many Chinese urban regions. In this study, a pilot-scale dual media filter was constructed to monitor its performance. The operational results indicated that the dual media filter performed well both on nitrification and on reduction of chemical oxygen demand. Microbial community structures at different sampling sites were also compared using $16 \mathrm{~S}$ ribosomal ribonucleic acid gene clone library analysis to identify the spatial heterogeneity the filter. Clone library analysis illustrated the difference of microbial community structure and an increase of microbial diversity along the filter depth. Moreover, potential pathogens from genera Chromobacterium and Sphingomonas were detected in the filter samples, which deserved further serious consideration in downstream treatment such as disinfection. These findings also provided an illustration of the utility of molecular techniques to discover microbial community change and potential pathogens in the drinking water biofilters.
\end{abstract}

Keywords Biofilter - Clone library - Disinfection . Granular activated carbon $\cdot$ Pathogen

\footnotetext{
S. Feng $\cdot$ C. Chen $\cdot$ X. J. Zhang $\cdot$ Z. Y. Yang School of Environment, Tsinghua University, Beijing 100084, China

Q. F. Wang · S. G. Xie $(\bowtie)$

College of Environmental Sciences and Engineering,

Peking University, Beijing 100871, China

e-mail: xiesg@pku.edu.cn
}

\section{Introduction}

In China, the predominant type of drinking water treatment processes is still the conventional treatment process (coagulation-flocculation, sedimentation, rapid sand filtration, and disinfection), which cannot remove the ammonia and organic matter effectively. Due to the deterioration of surface water quality, modification of conventional treatment process is under consideration by drinking water producers in many regions. However, with the rapid industrialization and urbanization, there is no space available for many water treatment works in China to introduce external advanced treatment units. Because biofiltration is an effective way to remove organic and nitrogen pollutants in drinking water, it seems a good option to retrofit a sand filter to a granular activated carbon (GAC)-sand dual media filter. In a GACsand dual media filter, organic matter and ammonium could be effectively removed by the GAC, while the sand could minimize the turbidity in the filter effluent (Emelko et al. 2006; Kim and Kang 2008; Wiesner et al. 1987). However, in China, the performance of the GAC-sand dual media filter has not been investigated in detail, which constrains the potential application of this promising technology. Identification of microbial structure could aid in the knowledge of the processes occurring in drinking water biofilters. The culture-dependent methods have found many applications in identification of microorganisms in drinking water biofilters (Cunliffe 1991; Moll et al. 1998; Norton and LeChevallier 2000). To circumvent some limitations associated with culturing techniques, few investigations using molecular techniques have recently been conducted to obtain information regarding the composition of microbial communities in drinking water biofilters ( $\mathrm{Li}$ et al. 2010).

The creation of biological activated carbon (BAC) and composition of microbial community colonizing GAC are 
important to the biodegradation capacity of these systems (Niemi et al. 2009). However, the information about microbial structure in BAC filter is still very limited.

Microbial communities in natural aquatic habitats are very sensitive to environmental perturbations (Paerl et al. 2003). Microbial community composition might be related to many environmental factors, including dissolved oxygen (DO) (De Wever et al. 2005), nutrients (Lindstrom 2000), and organic matter (Crump et al. 2003). In drinking water biofilter, ammonia, organic matter, and DO are gradually consumed by the microorganisms in the biofilm along the filter layer depth. However, little is known about the spatial heterogeneity of microbial structures in drinking water biofilter. Only a recent work has shown the spatial variation in nitrifying bacterial community in laboratory-scale BAC filters (Yapsakli et al. 2010).

In the current study, a pilot-scale GAC-sand dual media filter used for drinking water treatment was constructed to evaluate its performance in reduction of organic matter and nitrogen compounds. $16 \mathrm{~S}$ ribosomal ribonucleic acid (rRNA) gene clone library analysis was applied to elucidate spatial heterogeneity of microbial community structures along the filter depth in the biofilter. Moreover, although the threats of human pathogens in drinking water distribution systems have been reviewed in detail (Berry et al. 2006; Brettar and Höfle 2008), information on the existence of pathogens in the drinking water biofilter is very scant. The composition of microbial community in biofilter is important as a possible source of water contamination in the distribution system (Niemi et al. 2009). Therefore, the presence of potential pathogens was also investigated in this study, which might affect downstream treatment such as disinfection. Pilot-scale GAC-sand dual media filter was operated and water samples were monitored from December 2010 to June 2011 in Dongguan City, China. Molecular analysis was carried out between June and August in 2011 at College of Environmental Sciences and Engineering, Peking University, China.

\section{Materials and methods}

\section{Experimental setup}

The filtration column was a Plexiglas cylinder (4 m length and $300 \mathrm{~mm}$ diameter), equipped with sampling ports for water, GAC, and sand (Fig. 1). Specifications of the filter are summarized in Table 1. The pilot filter was fed with settled water from the Dongguan Treatment Plant in down-flow mode with a hydraulic loading of $8 \mathrm{~m} / \mathrm{h}$. During this study, the $\mathrm{pH}$ values, oxygen concentrations, and temperatures of the settled water ranged between 7.2 and 7.5, 5.0 and 7.9 mg $\mathrm{O}_{2} / \mathrm{L}$, and 10 and $30{ }^{\circ} \mathrm{C}$, respectively. The pilot filter was backwashed every 3 days using non-chlorinated water (the effluent of full-scale rapid sand filter in the treatment plant). Before this study, the filters had been operated for about 4 months allowing for the maturation of biomass.

Analyses of water quality

For physicochemical analysis, triplicate water samples were collected from the influent and effluent of the pilot filter. Chemical oxygen demand $\left(\mathrm{COD}_{\mathrm{Mn}}, \mathrm{Mn}\right.$ stands for the permanganate), ammonium $\left(\mathrm{NH}_{4}{ }^{+}-\mathrm{N}\right)$, and nitrite $\left(\mathrm{NO}_{2}{ }^{-}-\mathrm{N}\right)$ were determined according to were determined according to the standard methods described by China Environmental Protection Agency (2002). DO and temperature were measured using a HACH HQ30d system, while $\mathrm{pH}$ was measured using a Hach HQ11d system.

Clone library analysis

GAC or sand samples for clone library analyses were collected on day 102. The samples from 0.2, 0.4, 0.8, and $1.2 \mathrm{~m}$ depth below the surface of the GAC layer were referred to as

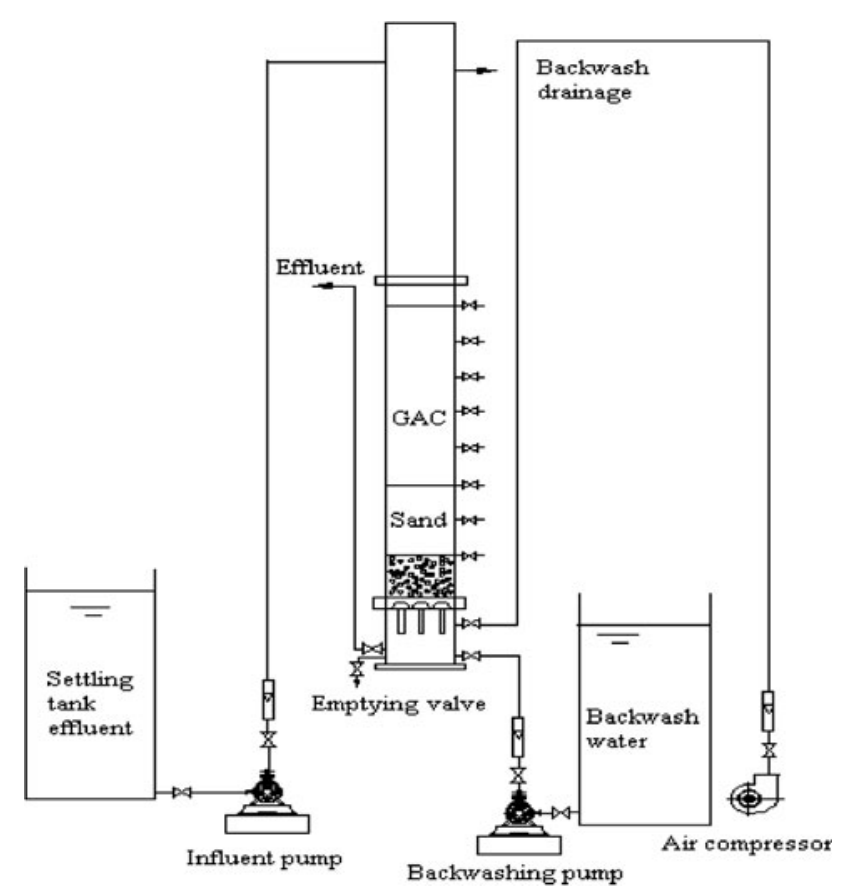

Fig. 1 Schematic of the pilot-scale GAC-sand dual media filter

Table 1 Specifications of the pilot-scale GAC-sand dual media filter

\begin{tabular}{llll}
\hline Characteristics & GAC & Sand & Gravel \\
\hline Depth (mm) & 1,000 & 400 & 300 \\
Effective size (mm) & 1.01 & 0.68 & \\
Uniformity coefficient & 1.54 & 1.61 & \\
\hline
\end{tabular}


Sample A, Sample B, Sample C, and Sample D, respectively. DNA of each sample was extracted using the UltraClean DNA extraction kit (Mobio Laboratories). Bacterial 16S rRNA genes were amplified using primers $27 \mathrm{~F}$ (5'-GAGTTTGATCMTGGCTCAG- $3^{\prime}$ ) and 1492R (5'-GGTTACC TTGTTACGACTT- $3^{\prime}$ ). PCR conditions were as previously described (Huang et al. 2011; Zhang et al. 2011). The PCR products were cloned into pGEM-T-easy Vector (Takara Corp, Japan). The white colonies were verified by PCR with primers M13 F (5'-TGTAAAACGACGGCCAGT-3') and M13 R (5'-AACAGCTATGACCATG-3'). Clones were sequenced at SinoGenoMax Co., Ltd. (Beijing).

Sequences identified as chimeras by Mallard software were excluded from further analyses (Ashelford et al. 2006). Clones sharing $\geq 97 \%$ identity were considered one operational taxonomic unit (OTU) using distance-based OTU and richness program (DOTUR) (Schloss and Handelsman 2005). Shannon diversity index was also calculated (Schloss and Handelsman 2005). Taxonomic identities of the sequences was obtained using the Ribosomal Database Project (RDP) II analysis tool "classifier" (Wang et al. 2007). The 16S rRNA sequences obtained in this study were submitted to GenBank under accession numbers JN389523-JN389586 (library with Sample A), JN389587-JN389652 (library with Sample B), JN389653-JN389715 (library with Sample C), and JN389716-JN389780 (library with Sample D).

\section{Results and discussion}

Reduction of organic matter and nitrogen pollutants in the pilot-scale filter

The pilot-scale GAC-sand dual media filter was continuously operated for nearly 160 days. The influent and effluent $\mathrm{COD}_{\mathrm{Mn}}$ concentrations in the bioreactor are presented with respect to time (Fig. 2). In the whole experimental period, an effective reduction of $\mathrm{COD}_{\mathrm{Mn}}$ in the pilot-scale filter was observed. Effective removal of $\mathrm{COD}_{\mathrm{Mn}}$ and other types of organic matter in the GAC-sand dual media filter was noted elsewhere (Zhang et al. 2004). Moreover, a recent investigation on full-scale bioreactors has also proven that the removal efficiency of organic matter was much higher in the GAC-sand dual media filter than in the sand filter (Kim and Kang 2008). Table 2 illustrates the effective reduction of $\mathrm{COD}_{\mathrm{Mn}}$ in the GAC layer, especially in the top 0.4-m GAC layer, while the reduction in the sand layer was negligible. Removal of most of the natural organic matter usually occurred at the top of the biofilters (Wang et al. 1995), which might be attributed to the decrease of attached biomass as filter depth increased (Wang et al. 1995; Yu et al. 2002).

Previous works on performance of BAC filters usually centered on organic carbon removal, however, effective

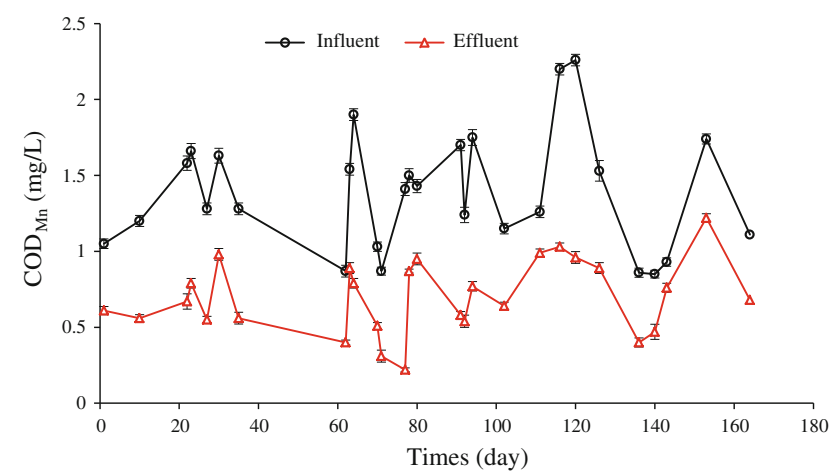

Fig. 2 Influent and effluent $\mathrm{COD}_{\mathrm{Mn}}$ concentrations in the GAC-sand dual media filter

Table 2 Changes of organic and nitrogen pollutants, and DO along the filter depth (on day 102)

\begin{tabular}{lllll}
\hline $\begin{array}{l}\text { Filter depth } \\
(\mathrm{m})^{\mathrm{a}}\end{array}$ & $\begin{array}{l}\mathrm{COD}_{\mathrm{Mn}} \\
(\mathrm{mg} / \mathrm{L})\end{array}$ & $\begin{array}{l}\text { Ammonia } \\
(\mathrm{mg} / \mathrm{L})\end{array}$ & $\begin{array}{l}\text { Nitrite } \\
(\mathrm{mg} / \mathrm{L})\end{array}$ & $\begin{array}{l}\mathrm{DO} \\
(\mathrm{mg} / \mathrm{L})\end{array}$ \\
\hline GAC layer & & & & \\
0 & 1.17 & 0.77 & 0.248 & 5.86 \\
0.2 & 1.05 & 0.44 & 0.124 & 3.87 \\
0.4 & 0.75 & 0.06 & 0.020 & 2.42 \\
1.0 & 0.64 & 0.04 & $<0.001$ & 1.80 \\
Sand layer & & & & \\
1.2 & 0.64 & 0.03 & $<0.001$ & 1.68 \\
1.4 & 0.64 & 0.03 & $<0.001$ & 1.64 \\
\hline
\end{tabular}

${ }^{a}$ Below the surface of the GAC layer

ammonia reduction could also occur in these biofilters (Yapsakli et al. 2010). Figures 3 and 4 represent the influent and effluent ammonia and nitrite concentrations in the pilot-scale GAC-sand dual media filter, respectively. A high ammonia removal was observed during the whole experimental period although the influent ammonia concentrations varied greatly. Moreover, the effluent nitrite concentrations always remained very low, usually below the detection limit. The high ammonia removal by the GAC-sand dual media filter has also been noted elsewhere (Zhang et al. 2004). Table 2 illustrates the significant ammonia and nitrite reduction in GAC layer (especially in the top 0.4-m GAC layer), in contrast to the negligible reduction in sand layer. Therefore, the reduction of both organic matter and nitrogen pollutants mainly occurred in the top 0.4-m GAC layer, which was also in accordance with the profile of DO consumption along the filter depth.

Identification of microbial community structures

Decrease of biomass and activity of attached microorganisms along the filter depth in the drinking water biofilters have been well documented (Wang et al. 1995; Yu et al. 


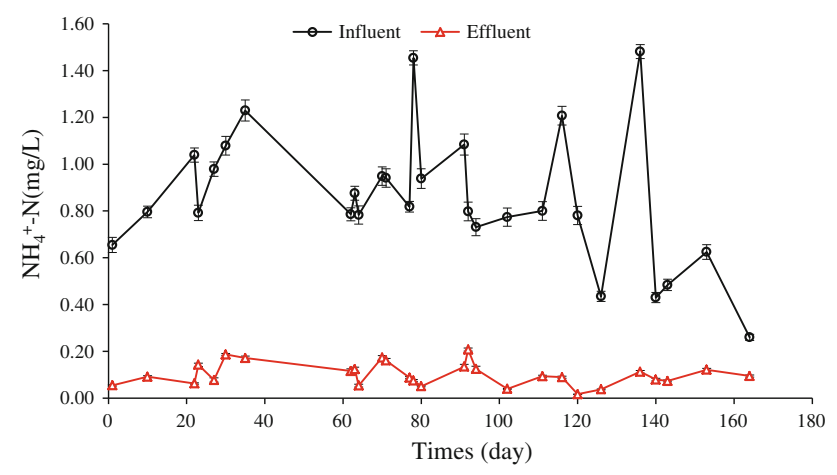

Fig. 3 Influent and effluent $\mathrm{NH}_{4}{ }^{+}-\mathrm{N}$ concentrations in the GAC-sand dual media filter

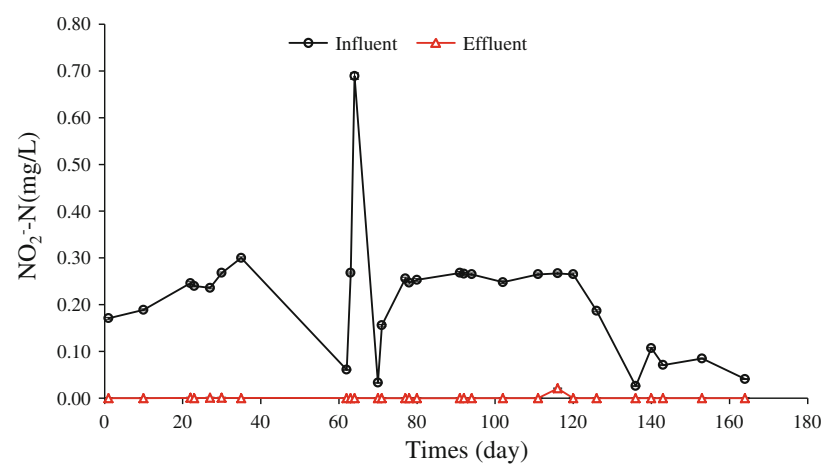

Fig. 4 Influent and effluent $\mathrm{NO}_{2}{ }^{-}-\mathrm{N}$ concentrations in the GAC-sand dual media filter

2002). However, little is known about the community structures and their spatial changes inside the drinking water biofilters. In this study, 16S rRNA gene clone library analysis was applied to elucidate spatial heterogeneity of microbial community structures. For each clone library, 63-66 clones were randomly selected. Figure 5 illustrates the changes of bacterial groups along the depth in the pilot filter. Alphaproteobacteria, Betaproteobacteria, Acidobacteria, Actinobacteria, and Planctomycetes were shared among all four samples. The major bacterial groups (with at least five sequences) in Sample A were Nitrospirae (31 sequences) and Alphaproteobacteria (21 sequences). However, Sample B were mainly composed of Alphaproteobacteria (37 sequences), Acidobacteria (8 sequences), Betaproteobacteria (6 sequences), and Bacteroidetes (5 sequences). Interestingly, Alphaproteobacteria, Acidobacteria, and Betaproteobacteria were also the largest three bacterial groups in Sample C and Sample D. Therefore, Sample B, Sample C and Sample $\mathrm{D}$ had similar major bacterial groups.

OTUs and Shannon diversity index were both determined at $3 \%$ sequence difference level by DOTUR program (Table 3). Table 3 shows that 23, 30, 41, and 43
OTUs were obtained in four bacterial libraries constructed with Sample A, Sample B, Sample C, and Sample D, respectively. Bacterial composition in drinking water biofilters varied with nutrient and DO levels (Niemi et al. 2009). The addition of phosphorus could significantly affect the microbial structure in the BAC filters ( $\mathrm{Li}$ et al. 2010). In this study, the change of Shannon index illustrates an increase of microbial diversity along the filter depth. This might be attributed to the reduction of pollutants and DO along the filter depth.

The compositions of community structure in BAC filter and sand filter are still poorly understood. A recent work showed that $68 \%$ of the isolated bacterial strains from a BAC filter were Betaproteobacteria and $25 \%$ to Alphaproteobacteria (Magic-Knezev et al. 2009). Niemi et al. (2009) also found the dominance of isolates belonging to Betaproteobacteria in a BAC filter in a pilot plant. Clone library analysis also indicated that Betaproteobacteria was the dominant bacterial group in the bench-scale BAC filter, operated for perchlorate and nitrate removal from contaminated groundwater, while Alphaproteobacteria was a minor bacterial group ( $\mathrm{Li}$ et al. 2010). However, in this study, Alphaproteobacteria were largest bacterial group in Sample B, Sample C and Sample D, and the second largest in Sample A. In contrast, Betaproteobacteria was much less abundant. The differences in the community structure composition were likely dependent on feed water.

Nitrospirae was the largest bacterial group in Sample A, but with a very low abundance in Sample B and Sample C, and no detection in Sample D. This was mainly responsible for the distinct difference of between Sample A and the other three samples. The dominance of Nitrospirae in Sample A suggested the strong nitrification process at the top of the filter $(0.2 \mathrm{~m}$ depth below the surface of the GAC layer). However, nitrification process could become increasingly weak along the filter depth with the rapid consumption of ammonia and nitrite. The very low abundance of Nitrospirae in Sample B might be attributed to the weak nitrification process in this region $(0.4 \mathrm{~m}$ depth below the surface of the GAC layer). Although the processes occurring in drinking water biofilters are well-understood, the information about the changes of nitrifier community structure in drinking water biofilters is very few. Yapsakli et al. (2010) showed the abundance of ammonia-oxidizing bacteria (AOB) decreased along the filter depth using realtime PCR technique.

As the second largest bacterial group in Sample B, Sample C, and Sample D (with 8-11 sequences), Acidobacteria was detected in Sample A with a very low abundance (with only one sequence). This also contributed greatly to the distinct difference of between Sample A and the other three samples. Acidobacteria was usually 
Fig. 5 Changes of bacterial groups in the pilot filter
- Sample A $\square$ Sample B $\square$ Sample C $\square$ Sample D

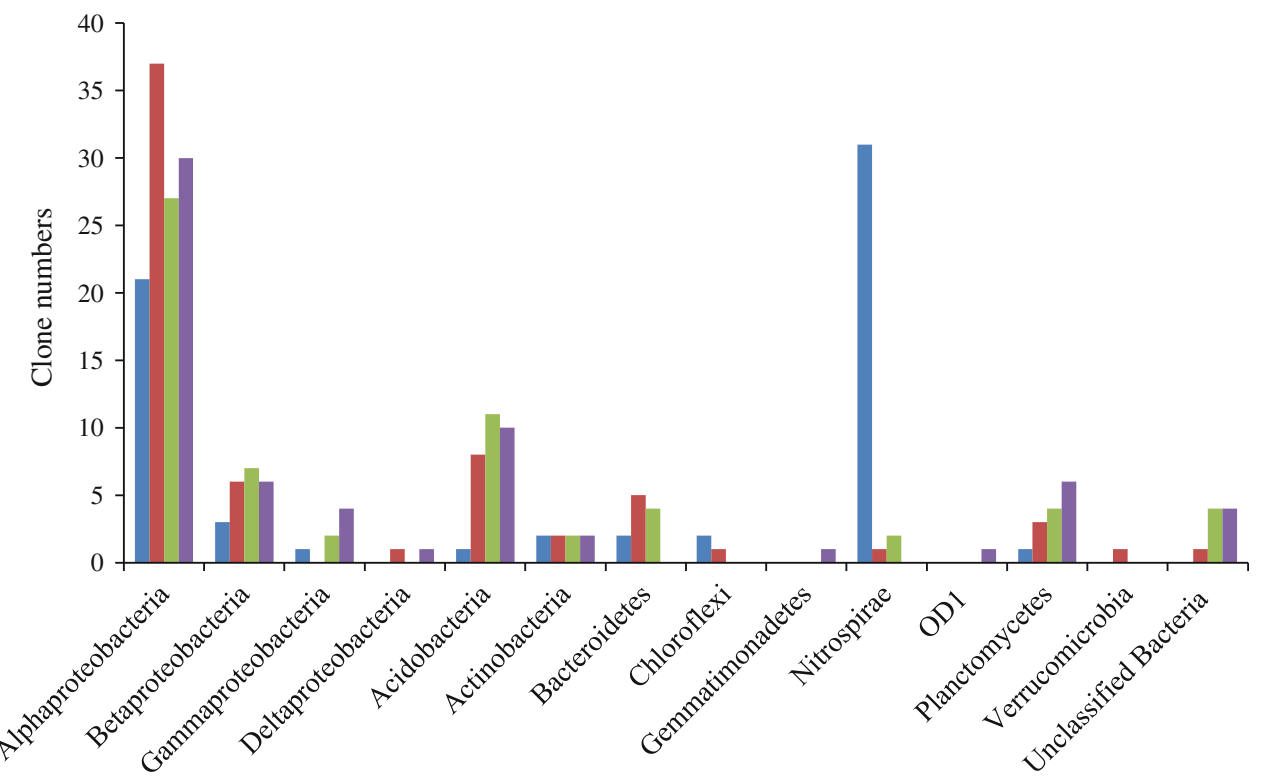

Table 3 OTUs and Shannon index (calculated at 0.03 difference level) of four clone libraries

\begin{tabular}{llll}
\hline Library & No. of clones & No. of OTUs & Shannon index \\
\hline Sample A & 64 & 23 & 2.3 \\
Sample B & 66 & 30 & 2.8 \\
Sample C & 63 & 41 & 3.5 \\
Sample D & 65 & 43 & 3.6 \\
\hline
\end{tabular}

abundant in soils (Griffiths et al. 2011; Sudini et al. 2011). However, little information exists on its presence in drinking water biofilters. Very low abundance of Acidobacteria was found in the BAC filter treating groundwater (Li et al. 2010).

\section{Potential microbiological risks}

The threats of human pathogens or opportunistic pathogens from many genera in drinking water distribution systems have been well documented (Berry et al. 2006; Brettar and Höfle 2008). However, pathogenic microorganisms in the drinking water biofilters have yielded little attention, although they are a possible source of water contamination in the distribution system. A large number of Sphingomonas species were detected in Sample C (7 sequences) and Sample D (6 sequences). Genus Sphingomonas is associated with a great variety of infections, and its infections caused by contaminated water sources have been reported (Toh et al. 2011). Therefore, the abundance of Sphingomonas species might pose a potential microbial risk in water supply.
One Chromobacterium species was detected in Sample A. Some members belonging to genus Chromobacterium are known or potential pathogens in mammals (Durán et al. 2010; Han et al. 2008). These organisms have been linked to many types of diseases, and there have been numerous reports of infection by these organisms in humans, some of which have led to fatalities (Baldi et al. 2010; Durán et al. 2010). Chromobacterium species were present in a pilot-scale microfiltration plant for drinking water treatment (Kwon et al. 2011). However, to the authors' knowledge, this is the first report concerning the existence of genus Chromobacterium in the drinking water filter. The hygienic significance of the presence of Chromobacterium species in the biofilter should be fully considered.

\section{Conclusion}

The pilot-scale GAC-sand dual media filter could effectively remove organic matter and nitrogen pollutants. The reductions mainly occurred at the top of the filter. $16 \mathrm{~S}$ rRNA gene clone library analysis illustrated a difference in microbial community structure, with increased microbial diversity occurring with filter depth. Alphaproteobacteria was one of the largest bacterial groups in all sampling sites, while phylum Nitrospirae predominated only in the $0.2 \mathrm{~m}$ depth. Two kinds of potential pathogens were detected in the filter, which implied potential microbiological risk in water supply. Further investigation on inactivation of potential pathogens by disinfection processes might be of practical importance for drinking water safety. 
Acknowledgments This work was financially supported by Major Science and Technology Program for Water Pollution Control and Treatment (2009ZX07423-003).

\section{References}

Ashelford KE, Chuzhanova NA, Fry JC, Jones AJ, Weightman AJ (2006) New screening software shows that most recent large 16S rRNA gene clone libraries contain chimeras. Appl Environ Microbiol 72:5734-5741. doi:10.1128/AEM.00556-06

Baldi M, Morales JA, Hernandez G, Jimenez M, Alfaro A, BarqueroCalvo E (2010) Chromobacterium violaceum infection in a freeranging howler monkey in Costa Rica. J Wildlife Dis 46: 306-310

Berry D, Xi C, Raskin L (2006) Microbial ecology of drinking water distribution systems. Curr Opin Biotechnol 17:297-302. doi: 10.1016/j.copbio.2006.05.007

Brettar I, Höfle MG (2008) Molecular assessment of bacterial pathogens-a contribution to drinking water safety. Curr Opin Biotechnol 19:274-280. doi:10.1016/j.copbio.2008.04.004

China Environmental Protection Agency (2002) Methods for water and wastewater determination. China Environmental Science Press, Beijing

Crump BC, Kling GW, Bahr M, Hobbie JE (2003) Bacterioplankton community shifts in an Arctic lake correlate with seasonal changes in organic matter source. Appl Environ Microbiol 69:2253-2268. doi:10.1128/AEM.69.4.2253-2268.2003

Cunliffe DA (1991) Bacterial nitrification in chloraminated water supplies. Appl Environ Microbiol 57:3399-3402

De Wever A, Muylaert K, Van der Gucht K, Pirlot S, Cocquyt C, Descy JP, Plisnier PD, Vyverman W (2005) Bacterial community composition in Lake Tanganyika: vertical and horizontal heterogeneity. Appl Environ Microbiol 71:5029-5037. doi: 10.1128/AEM.71.9.5029-5037.2005

Durán M, Faljoni-Alario A, Durán N (2010) Chromobacterium violaceum and its important metabolites-review. Folia Microbiol 55:535-547. doi:10.1007/s12223-010-0088-4

Emelko MB, Huck PM, Coffey BM, Smith EF (2006) Effects of media, backwash, and temperature on full-scale biological filtration. J Am Water Works Assoc 98:61-73

Griffiths RI, Thomson BC, James P, Bell T, Bailey M, Whiteley AS (2011) The bacterial biogeography of British soils. Environ Microbiol 13:1642-1654. doi:10.1111/j.1462-2920.2011.02480.x

Han XY, Han FS, Segal J (2008) Chromobacterium haemolyticum sp nov., a strongly haemolytic species. Int J Syst Evol Microbiol 58:1398-1403. doi:10.1099/ijs.0.64681-0

Huang Y, Zou L, Zhang SY, Xie SG (2011) Comparison of bacterioplankton communities in three heavily polluted streams in China. Biomed Environ Sci 24:140-145. doi:10.3967/ 0895-3988.2011.02.008

Kim J, Kang B (2008) DBPs removal in GAC filter-adsorber. Water Res 42:145-152

Kwon S, Moon E, Kim TS, Hong S, Park HD (2011) Pyrosequencing demonstrated complex microbial communities in a membrane filtration system for a drinking water treatment plant. Microbes Environ 26:149-155. doi:10.1264/jsme2.ME10205

Li X, Upadhyaya G, Yuen W, Brown J, Morgenroth E, Raskin L (2010) Changes in the structure and function of microbial communities in drinking water treatment bioreactors upon addition of phosphorus. Appl Environ Microbiol 76:7473-7481. doi:10.1128/AEM.01232-10

Lindstrom ES (2000) Bacterioplankton community composition in five lakes differing in trophic status and humic content. Microbial Ecol 40:104-113

Magic-Knezev A, Wullings B, Van der Kooij D (2009) Polaromonas and Hydrogenophaga species are the predominant bacteria cultured from granular activated carbon filters in water treatment. J Appl Microbiol 107:944-953. doi:10.1111/j.1365-2672. 2009.04337.x

Moll DM, Summers RS, Breen A (1998) Microbial characterization of biological filters used for drinking water treatment. Appl Environ Microbiol 64:2755-2759

Niemi RM, Heiskanen I, Heine R, Rapala J (2009) Previously uncultured $\beta$-Proteobacteria dominate in biologically active granular activated carbon (BAC) filters. Water Res 43:50755086. doi:10.1016/j.watres.2009.08.037

Norton CD, LeChevallier MW (2000) A pilot study of bacteriological population changes through potable water treatment and distribution. Appl Environ Microbiol 66:268-276

Paerl HW, Dyble J, Moisander PH, Noble RT, Piehler MF, Pinckney JL, Steppe TF, Twomey L, Valdes LM (2003) Microbial indicators of aquatic ecosystem change: current applications to eutrophication studies. FEMS Microbiol Ecol 46:233-246. doi: 10.1016/S0168-6496(03)00200-9

Schloss PD, Handelsman J (2005) Introducing DOTUR, a computer program for defining operational taxonomic units and estimating species richness. Appl Environ Microbiol 71:1501-1506. doi: 10.1128/AEM.71.3.1501-1506.2005

Sudini H, Liles MR, Arias CR, Bowen KL, Huettel RN (2011) Exploring soil bacterial communities in different peanut-cropping sequences using multiple molecular approaches. Phytopathology 101:819-827. doi:10.1094/PHYTO-11-10-0310

Toh HS, Tay HT, Kuar WK, Weng TC, Tang HJ, Tan CK (2011) Risk factors associated with Sphingomonas paucimobilis infection. J Microbiol Immunol Infect 44:289-295. doi:10.1016/j.jmii. 2010.08.007

Wang JZ, Summers RS, Miltner RJ (1995) Biofiltration performance: part 1 relationship to biomass. J Am Water Works Assoc 87: $55-64$

Wang Q, Garrity GM, Tiedje JM, Cole JR (2007) Naïve Bayesian classifier for rapid assignment of rRNA sequences into the new bacterial taxonomy. Appl Environ Microbiol 73:5261-5267. doi: 10.1128/AEM.00062-07

Wiesner MR, Rook JJ, Fiessinger F (1987) Optimizing the placement of GAC filtration units. J Am Water Works Assoc 79:39-49

Yapsakli K, Mertoglu B, Cecen F (2010) Identification of nitrifiers and nitrification performance in drinking water biological activated carbon (BAC) filtration. Process Biochem 45:15431549. doi:10.1016/j.procbio.2010.06.004

Yu X, Zhang XJ, Wang ZS (2002) Biomass measurement in drinking water biofilters using phospholipid analytical technique. Water Wastewater Eng 28:1-6

Zhang C, Zeng GM, Yu J, Fu GK, Ren WH (2004) Character of the treating micro-polluted source water with GAC-sand biofiltration. China Environ Sci 24:209-213

Zhang SY, Wang QF, Xie SG (2011) Microbial community changes in contaminated soils in response to phenanthrene amendment. Int J Environ Sci Technol 8:321-330 